\title{
Puppet Shows: Inspiring Nationalism and Raising Tourism Awareness for Egyptian Children Nahla Nasser Maii Baher
}

\author{
Faculty of Touris m and Hotel Management, Helwan University
}

\begin{abstract}
This study sheds light on the importance of revitalization of the puppet shows in Egypt and its role in inspiring nationalism and raising tourism awareness for children. Puppetry has played an important role in disseminating knowledge in most parts of the world. Puppetry has been used traditionally in Egypt as a popular and an inexpensive medium to transmit knowledge about Egypt myths and legends. It is a dynamic art form that appeals to all age groups, this medium of communication has been selected to serve as an aid for rising tourism awareness either tangible or intangible for children. Concerning this issue, a very few children understand the importance of their heritage. Most of the children going to primary school remain within the narrow confines of the teaching and learning environment of their school, and most of them do not know anything about the broader issues of the heritage around them. The research was conducted to assess how can the puppet show inspire and bloom the desire of nationalism inside young children of the age between 6 and 12 years. For this purpose, a questionnaire survey was administered and distributed among 250 child whom were exposed to tourism knowledge through the puppet shows in a primary school, and also a focus group interview was employed with a group of ten puppeteers who perform entertainment puppet shows in The Cairo Puppet Theatre. The Results revealed that puppets are easier to transmit knowledge for children. They are an indirect educational tool to create fidelity and loyalty to their country as well as tourism awareness.
\end{abstract}

Keywords: Puppetry, puppet show, nationalism, tourism awareness.

\section{Introduction}

"Nationalism" is defined as "the pshyological state that individual citizen maintains high fidelity and loyalty to the nation and state" (Zhang, 2008:161). Nationalism reflects a strong feeling of accredits and belonging to nation's history and traditional culture, emphasizing the consciousness, character and the devotion to the interests of a particular state (Fahua, 2016). It creates a sense of appreciation for the different areas around them in their state. Most states are continually seeking to create, increase and enhance such devotion. They employ many methods directly or indirectly to enhance it through national sports or domestic travel, or direct methods using mediums as publications, motion pictures and radio.

In this review, Puppet shows were utilized by teachers through different educational levels to illustrate tourism impacts, highlight and demonstrate tourist places using children's literature. Through the show, one can learn how to appreciate the different tourist areas as they present the locations of the story, implement the different ethics and traditions through the consequence of the story narrated. This paper is trying to illustrate a link of national identity construction and tourism awareness through the usage of a most preferable and powerful mean imposed on children, which is the puppet show.

\section{Literature Review}

\section{Brief history of Puppetry}

Puppetry is a very ancient art form, thought to have originated about 3000 years ago. Puppets have been used since the earliest times to animate and communicate the ideas and needs of human societies. Some historians claim that they pre-date actors in theatre. There is evidence that they were used in Egypt as early as 2000 $\mathrm{BC}$, when string-operated figures of wood were manipulated to perform the action of kneading bread (Logan, 2007). Wire controlled, articulated puppets made of clay and ivory have also been found in Egyptian tombs Hieroglyphs also describe "walking statues" being used in Ancient Egyptian religious dramas. Puppetry was practiced in Ancient Greece and the oldest written records of puppetry can be found in the works of Herodotus and Xenophon, dating from the 5th century BC (Hussein, 2012). 
In the $19^{\text {th }}$ century, puppetry faced great competition from other forms of theatre such as vaudeville and music hall, but it still adapted to these challenges, by developing stage acts and participating in the new forms of popular theatre (Logan, 2007). Although many film media techniques, cinema and television were greatly developed through the $20^{\text {th }}$ century, puppetry remained one of the main aspects of the folk roots and traditional means of heritage. It reached large audience as it attracted both adults and children. Cultural variations of puppetry developed independently in many parts of the world, with unique types still carried on today in Japan, China, Germany, Indonesia, and the United States, among other places (Kenneth, 2011). Some particular puppets became international icons in the age of television, including Howdy Doody, Lamp Chop, and Jim Henson's Muppets. In many countries such as Japan, Vietname, Indonesia, and the United States. Ceremonial puppets were used to demonstrate cultural values. But in Europe, it was used in the production of morality plays by the children church (Bell, 2000).

At the beginning of the $21^{\text {th }}$ century, a cultural mindset arose in Europe and the United States in which puppets began to be used in an experimental way, aimed solely at adult audiences (Logan, 2007). Whether the focus is on adult or child enjoyment of puppets, there are regional puppet guilds and societies through the United States, Europe, and other parts of the world. Several national and international museums also exist to celebrate the history of puppets.

\section{Types of Puppets}

Puppetry is a form of theatre or performance that involves the manipulation of puppets inanimate objects, often resembling some type of human or animal figure, that are animated or manipulated by a human called a puppeteer. Such a performance is also known as a puppet show or a puppet play (Currell, 1992). The puppeteer uses movements of her hands, arms, or control devices such as rods or strings to move the body, head, limbs, and in some cases the mouth and eyes of the puppet. The puppeteer often speaks in the voice of the character of the puppet, and then synchronizes the movements of the puppet's mouth with this spoken part (Kenneth, 2011). The actions, gestures and spoken parts acted out by the puppets are typically used in storytelling. They are made of a wide range of materials, depending on their form and intended use. There are many different varieties of puppets such as finger puppet, live-hand puppet, light curtain puppet, string puppets, rod puppets, water puppet (Synovitz 1999; Tytti, 2012).

\section{Importance of puppet show to children}

Puppets became an aspect of our history and everyday lives. From Marionettes to the Muppets we see them on television, on videos or in live performances. It appeals to both old and young alike, representing different customs and traditions and are valuable educational tools. Puppets are both entertaining and captivating (Malkanthi, 2016). Children can believe and relate to them; they can enter and explore the fascinating world that puppets create. Puppets provide an essential link between learning and play which makes them wonderful teaching tools for at home, the classroom and in the wider community (Sinclair, 2004). Learning through play is fundamental to our children's education, helping them to develop the necessary skills in life. Puppets can stimulate children's imagination, encourage creative play and discovery and are a wonderful interactive way to introduce narrative to even the most reluctant reader (Schrandt, et. al, 2009; Paccuulio and Machado, 2016). They can be a powerful way of bringing story time to life; puppets can provide a focus for role play, encouraging the child's imagination and involvement in activities and can play a fundamental part in the recitation of stories and verse (VanSchuyver, 1993).

Puppets can break down barriers and provide an effective means to initiate communication. Several authors emphasized that using puppets as a communication tool is more appropriate with younger children (Berger, 1980; Eder, 1990; Measelle et al. 1998). The child trusts the puppet and doesn't feel threatened by it, making it a perfect neutral medium through which they can discuss sensitive issues (George, 1994; Salmon and Sainato, 2005). Puppets can motivate and support children with difficulties in communication and interaction. They can help to develop their social and motor skills, and can meet the visual, tactile and emotional needs of the individual child (Luckenbill, 2011). Puppets can share joy or sadness; they can be naughty or good; and when a child is engaged by a puppet they can learn lessons without even realizing. When children use puppets to tell stories, a number of cognitive skills come into play (Salmon and Sainato, 2005). And it can also be used to instill vital human characteristics such as generosity, passion and harmony in to the minds of people (Gibson et al., 2010). 
Puppetry has been used with children as a therapeutic tool by health professionals. Several studies highlight the positive effects of using a puppet including: decreasing children's fears (Hawkins, 1991; Stewart et al., 1994) and anxiety levels (Zahr 1998); helping children cope with illness and surgery (Walker 1988; Paccuulio and Machado2016); teaching children health promotion strategies ( Synovitz 1999); and helping children adjust to the hospital environment (Schmidt 2002; Pelicand et al., 2006). Therefore, the effectiveness of puppets as communication tools has been clearly demonstrated.

\section{Preservation of culture through puppet shows}

The "Aragoz" which was introduced by Ottomans in Egypt, became a main source of entertainment for the amusement of both children and adults. It reflected the socio-economic, cultural, traditional and historical forces of the society through its array (Hussein, 2012). The appreciation by the Egyptians of the idea of puppetry performance turned the Aragoz into a significant folklore character. They used it to criticized aspects of lifestyles enhance Egyptian characters and preserve traditions and cultures.

Nevertheless, the puppet became less popular in Egypt between the 1970s and 1990s due to a sharp decline in the number of skilled and experienced puppeteers, and because of the spread of competing TV programs, satellite channels, and other means of entertainment that targeted and attracted children. Currently, many Egyptian entertainers are attempting to revitalise Aragoz. Yet, instead of obligating to the physical features, sketches, and language of the traditional Aragoz form, they have started to refurbish the puppet and its moral messages to conform to those of contemporary society (Hussein, 2012).

There will be many opportunities to puppetry performing to help their community to define its current and past identities for itself as well as others. Thus, the puppet shows are the most important carrier for culture elements from one generation to another. These shows have been responsible for sustaining the long continuities of ancient traditions. They are the link between the past and the present (Bowitz and Ibenhot, 2009).

\section{Role of puppet shows in tourism awareness}

Children often communicate more easily with puppets, giving them confidence to express their ideas and feelings (Sparapani. et al., 2014; Paccuulio. and Machado, 2016). It can be used as an effective tool to create a strong feeling towards their country and a great awareness of their history and tourist attractions. The puppetry shows can be organized at places like temples and public halls and may be available on historical and religious events. It is can be used as a wonderful tool to attract tourism to aid the development and promotion of these areas' economies (MacDonald and Jolliffe, 2003; OECD, 2008).

Puppets are an effective tool in education through narrating the history of the country, describing its geographical aspects through the reaction between puppets. Knowledge learned in this way are more likely to be remembered and to become part of children's solid stock of knowledge. The puppet shows can be used to stage events of religious stories, ancient stories, narrate legends, implement ethics and illustrate traditional music and dance (Malkanthi, 2016). The teachers and puppeteers can design the act using the decorations sets as well as illustrating the consequence of the act, to serve the idea of welcoming tourists in the different attractions of the nation. Also setting the ideas of communication, services offered and dealings of both locals and visitors in a huge similar to "El Leila El Kibeera,", one of the most recognizable act in our nation.

\section{Research Design and Methodology}

Mixed-Methodology was used to gather the requested data. Normally, implementing both methods of qualitative and quantitative approaches provides a better understanding of the research problem (Bryman and Bell, 2007). Data collected through a questionnaire that was distributed among 250 child between the ages of (6-12) years in a primary school. School-aged children have already developed cognitive abilities to differentiate their own ideas from others and to express them verbally. They are also capable of dominating symbols and using memoirs of past experiences to evaluate, interpret, and decide about the present (Punch, 2002; Hockenberry et al., 2006). The questionnaires were distributed among the children after obtaining an approval from the school administrative to undergo the study. A total of 250 questionnaire were distributed and 220 were collected. Only 200 questionnaires were valid for analysis after the elimination of the 
incomplete ones. This represented(80\%) as a response rate, The survey includes questions about their community, country, and their friends, after being exposed to legend stories created by teachers to establish ideas of community belonging, accepting others, loving their school, home, community. As well as, accepting tourist and being proud to welcome tourism in their country. This show held in their school event "Culture Day" which was organized by the school.

Also a focus group interview was done with a group of puppeteers (ten puppeteers) who perform entertainment puppet shows in the Cairo Puppet Theatre. Focus group research was employed in the current study as it has the potential to highlight the importance of revitalization of puppet shows and to facilitate a better understanding of how can puppet shows create and bloom the desire of nationalism inside young children. It can be argued that focus groups offer a more natural environment than that of individual interviews, as participants are interacting with other people, just as they do in real life (Krueger and Casey, 2000).

\section{Part 1: Children's questionnaires}

Table 1. The demographic characteristics of respondents

\begin{tabular}{|l|c|c|}
\hline Characteristics & Frequency & Percentage \\
\hline Gender & 80 & 40 \\
\hline Boy & 120 & 60 \\
\hline Girl & \multicolumn{3}{|l}{} \\
\hline Age group & 40 & 20 \\
\hline $6-8$ & 70 & 35 \\
\hline $8-10$ & 90 & 45 \\
\hline $10-12$ & &
\end{tabular}

The demographic characteristics of respondents were assessed in terms of gender and age group. It is apparent from Table 1 that the number of girls who took the survey exceeds the number of boys by a number of 40 girl accounting for (60\%) and boys for (40\%). The majority of respondents were between 10-12 years old $(45 \%)$ that exceeds those between 8-10 years old (35\%) and 6-8 years old (20\%) respectively. The age of the participants was limited to (6-12) years as this age can absorb themes easily and can communicate effectively.

Table 2. Attending the puppet show created by the school

\begin{tabular}{|l|c|c|}
\hline $\begin{array}{c}\text { Do you attend the puppet } \\
\text { show }\end{array}$ & Frequency & percent \\
\hline Yes & 125 & 75 \\
\hline No & 50 & 25 \\
\hline Total & 200 & 100 \\
\hline
\end{tabular}


The results in table 2 illustrate show that (75\%) of the children attend and join the puppet shows while ( 25 $\%$ ) of the respondents did not attend due to absence. By this, analysis was implemented only on the group whom were exposed to the show $(\mathrm{N}=125)$ eliminating the group who did not attend the show. It was clearly observed that the children who were exposed to knowledge through the puppet shows were most reliable to answer the questions and were able to express themselves more than others.

The questionnaire started with a request to draw themselves. Most of the children (90\%) were influenced by the puppets they saw in the shows, they draw themselves like the puppets. Then they started to describe their friends, family members, and neighbors. Setting the common things between them and what they usually share.

Table 3.The as pects that the $y$ were influenced most by

\begin{tabular}{|l|c|c|}
\hline Which of the following influence you more & Frequency & Rank \\
\hline The way the puppets talk & 59 & 4 \\
\hline The way the puppets dress & 40 & 5 \\
\hline The songs and music played & 77 & 3 \\
\hline The legend stories narrated & 90 & 2 \\
\hline The puppet appearance & 100 & 1 \\
\hline
\end{tabular}

*Available more than one choice. * $(\mathrm{N}=125)$

Table 3 demonstrates that the children were influenced most by the puppet appearance followed by the legend stories narrated (ranked 2), followed by that they were influenced by the songs and music played (ranked 3), after that came the way the puppet talk, then the way they dress. This illustrates that children are most attracted to puppets characters, perceive them as living creatures and attribute many different roles to them in playtime. This is in agreement with that of Bromfield (1995) as he emphasized that puppet's appearance is an important issue to consider. Puppets that are pleasing to the eye and touch are recommended as they may provide greater opportunity for expression.

Table 4. The things they like most about their country

\begin{tabular}{|l|c|c|}
\hline $\begin{array}{l}\text { What do you like about you country while } \\
\text { watching the show }\end{array}$ & Frequency & Rank \\
\hline I like its people and culture & 87 & 2 \\
\hline I want to visit the historical places & 106 & 1 \\
\hline I like the things they do in the country & 50 & 3 \\
\hline
\end{tabular}

*Available more than one choice. *(N=125)

They were asked what they like about their country while they were watching the puppet show. The results in table 4 indicated that the children liked most the people and culture of their country. The second largest number of respondents pointed out that they wanted to visit the historical places they learned about in the stories, while liking the things they do in their country had the lowest frequency. This question illustrated 
that how the information set through the show penetrated the young minds and create the desire to visit such places and a strong feeling towards their people and country.

Table 5. Affection for the ir country

\begin{tabular}{|l|c|c|}
\hline $\begin{array}{l}\text { How can you show your affection for your } \\
\text { country }\end{array}$ & Frequency & Rank \\
\hline I will work hard to make it better & 59 & 4 \\
\hline I will clean it & 89 & 3 \\
\hline $\begin{array}{l}\text { I am going to draw pictures and invite people to } \\
\text { visit it }\end{array}$ & 125 & 1 \\
\hline I would like to sing songs for my country & 94 & 2 \\
\hline
\end{tabular}

*Available more than one choice. * $(\mathrm{N}=125)$

All the respondents announced that they are going to draw pictures and invite people to visit their country, The second largest number of respondents indicated that they would like to sing songs for their country, while cleaning their country (ranked three) and working hard to make their country better had the lowest frequency. This emphasizes the positive effect puppets have on children to express their feelings and thoughts, which would otherwise remain hidden. In this respect, several authors emphasized that puppets can be beneficial for effective communication and to explore children's opinions and narratives (Sinclair, 2004; Jongudomkarn et al., 2006).

Table 6. Welcoming tourists to their country

\begin{tabular}{|l|l|l|l|}
\hline Do you like tourists to come to your country & Frequency & & percent \\
\hline Yes & 111 & & 88.8 \\
\hline No & 14 & & 11.2 \\
\hline Total & 125 & & 100 \\
\hline
\end{tabular}

$*(\mathrm{~N}=125)$

Table 6 shows that the majority of respondents (88.8\%) agreed that they like tourists to come to their country which means that the children are very influenced by the puppet show they were exposed to. This indicates that puppet show can be used as an important tool for transmitting tourism knowledge for their ability to integrate art, communication and persuasion. Therefore, watching a puppet show allows the children to reflect on what they see and hear - it engages parts of the brain that process experience, reason and thinking things through. The puppets present social and behavioral concepts that children can practice right there on the spot and then take away with them once puppets leave.

\section{Part 2: Focus group interview}

Focus group interview covered various themes related to the puppeteers' familiarity with the importance of puppet shows to raise nationalism, the thematic modifications they added to the shows, the value of the puppet shows to the Egyptians, the reasons for the declining popularity of the puppet in Egypt, and the revitalization of the puppet shows again. The ten puppeteers interviewed ranged in age from 30 to 41 years. 
Less than half of the sample finished their college education while the remainder did not pass their secondary education. All of the puppeteers interviewed were male. Although they did not specifically confirm that a puppeteer should be male, but they referred to the hard physical requirements of the job and constant mobility that could not be undertaken by a woman.

As explained by most of the puppeteers $(80 \%)$ when they were asked about the value of the puppet show to the Egyptians, they confirmed that "Aragoz shows" were considered the main folklore theme, and the principal source of amusement for children and their families. Also, (20\%) of the respondents added that it was used as a social mechanism to express their opinions, to resist occupation, and to criticize wealthy Egyptians and their deplorable habits.

"It was used as a mean of expressing their criticism of certain duplicitous characters in society or types of social bad behaviour"

"It was as a device for "criticism" of their rulers in hidden jokes and amusing witticism".

"It was a principal source of amusement for children and their families and Aragoz street shows were propagated on a large scale".

When asked how the expansion of television and cinema affected the popularity of puppet show, (70\%) of the respondents claimed that due to the spread of television and cinema and other modern entertainment and communication forms puppetry diminished. Moreover, (30\%) of the puppeteers clarified that most skilled puppeteers either died or had become very old, a situation that threatened the handicraft of wooden puppet making in Egypt and thus the existence of Aragoz puppetry altogether. On the other hand, Entertainment puppetry shows stared to appear in the 1990s as a celebration shows on children's special occasions such as birthdays.

'Entertainment shows celebrated children's birthdays became a new fashion among most upper middle and upper class families"

Entertainment shows diffused too many restaurants, schools and hotels to attract and amuse children"

Most respondents (85\%) mentioned that they modified some of the basic physical characteristics of the puppet, using imported plastic dolls rather than the traditional hand-made wooden puppets, and, adapting some of the theatrical sketches and narratives for contemporary audiences. This findings is in agreement with that of (Hussein, 2012).

"It was normal for Aragoz to punish others with a stick to conform. That was a normal scene in the past but today is not."

"The stick of Aragoz was used against those whose behaviours needed to be corrected. No one was offended by those scenes, which we do not present today"

By asking the puppeteers about the factors that aid in revitalization of puppet shows in Egypt, after discussion $(70 \%)$ of them suggested that government and researches should focus on traditional puppetry art to regain its popularity and also to organize touristic puppet show at the most famous areas in the country This step will generate a global level of awareness and will facilitate obtaining foreign assistance while ensuring sustainability..

"At national level the government, universities, researchers and other interested parties should focus on traditional art which is recognized at International level. This will help to develop and popularize the puppetry art". 
"I suggest to organize puppet shows for tourists at the most famous areas to stage ancient stories, religuos stories, and traditonal music".

Most of the respondents (90\%) believed that by modifying some of puppets basic characteristics of behavior, the puppet shows would regain its popularity, thus keeping the historic figure in the minds of Egyptians for years to come. Moreover, they confirmed that the art of puppetry-making must be revived.

The final part of the interview revolved around a number of questions aimed at generating discussion on potential ways that puppet shows might inspire nationalism and tourism awareness. (70\%) of the respondents thought that the academics and scholars will get opportunity to conduct research studies, prepare papers on this trade while opportunities are available to include puppetry art in to school and university activities. Some of the respondents (30\%) clarified that the writing and singing script should be modified in the context of tourism. Then, Puppet Maker, Puppeteer, Painter, Make-up Artiste, Musician, Dubbing Artiste, and Electrician should plan the shows using the culture and traditional themes of the nation to use as a marketing tool and an indirect tool of knowledge.

\section{Conclusion and Recommendations}

As mentioned previously, the puppetry industry is a very rich one; that can enhance the inspiration of nationalism and highlight the awareness of tourism industry. Puppetry's role is still vital in introducing and creating ideas and knowledge into the minds of children. This study provides detailed understanding of how can puppet shows inspire and bloom the desire of nationalism inside young children, through the demonstration of legends, traditions, and main culture features. It can also be used to serve their purpose and other purposes of marketing if implemented in touristic attractions, as the famous play of "El Leila El Kibeera". The idea of craving the feeling of love and appreciation can be inspired through the scripts used by teachers, actors and puppeteers to achieve the goals of nationalism and appreciation of tourist attractions. Puppet shows can be used by media as a safeguard for the intangible culture heritage. Children can be more aware of their history and the historical attractions and then they will participate in the preservation, promotion and dissemination of the unique culture and heritage in parallel with the advancement and overall development of their country.

As the findings of this study proved the anticipation and participation of the children between the ages of 612 years. Their idea of involvement in to their community and country proved to be positive after attending a puppet show inspiring them with their role towards their country and how to appreciate the tourist attraction representing their past. Secondly, another approach would be to obtain the tourism industry's perspective on the topic by interviewing experts working within the tourism industry. It would be worthwhile for future research as well to investigate the proposed role of the teachers in using this effective tool to create fidelity to their country as well as tourism awareness. Therefore, as recommended that this approach can be used in elementary schools, tourist areas, and special children programs in the media. Recommendations can be approached to the Ministry of Education, Ministry of Culture as well as Ministry of tourism to combine their efforts as to revitalize this industry and art of puppetry to implement heritage conservation, history appreciation and knowledge to create well informed, loyal and creative generation capable of serving their country and enjoying its beauty attractions.

\section{References}

Bacuez, J. (2009). Intangible Heritage Tourism and raising awareness on Kilwa Kisiswani and Sorgo Mnara, World Heritage site of kilwa, United Republic of Tanzania: 15-19.

Bell, J. (2000). Strings, Hands, Shadows: A Modern Puppet History, Wayne State UniversityDetroit Institute of Art, Press. P13.

Berger, L. (1980). The winnicott squiggle game: A vehicle for communicating with the school-aged child. Pediatrics 66: 921-4

Blumenthal, E. (2005). Puppetry and Puppets, Thames and Hudson.P12. 
Bowitz, E. and Ibenhot, K. (2009). Economic impacts of cultural heritage - Research and Perspectives, Journal of Cultural Heritage 10 (1):1-8 .

Contreras, G. (1995). Teaching about Vietnamese culture: water puppetry as the soul of the rice fields, Journal of Social Studies 8 (1): 25-28.

Currell, D. (1992). An Introduction to Puppets and Puppet Making. London: New Burlington. Quintet Publishing Limited: 23-24.

Eder, R. (1990). Uncovering young children's psychological selves: Individual and developmental differences. Child Development 61: 849-63.

George, S. (1994). Use puppets in your teaching. New Engl Reading Association 30 (3): 26-29.

Ghosh, S. and Bane rjee, U. (2006). Indian Puppets, Abhinav Publications: 1-4

Gibson, F., Aldiss, S., Horstman, M., Kumpunen, S.,and Richardson, A. (2010). Children and young people's experiences of cancer care: a qualitative research study using participatory methods. International Journal of Nursery Study 47: 1397-1407.

Hawkins, E. (1991). Bravery training: An approach to desensitizing young children to fears encountered in the hospital setting. Archives of Physical Medicine and Rehabilitation 72: 697-700

Hussein, N. (2012). The Revitalisation of the Aragoz Puppet in Egypt: some Reflections Popular Entertainment Studies. Published by the School of Drama, Fine Art and Music, Faculty of Education and Arts, The University of Newcastle, Australi. 3(1): 57-70.

Jongudomkarn D., Aungsupakorn, N., and Camfield, L. (2006). The meanings of pain: a qualitative study of the perspectives of children living with pain in North-Eastern Thailand. Nursery Health Science 8: 156-163

Kenneth, G. (2011). Puppet: An Essay on Uncanny Life. Chicago: University of Chicago Press. P.23.

Latshaw, G. (2000). The Complete Book of Puppetry, Dover Publications. Books, Quintet Publishing Limited. London: 14-16.

Lindquist T. (1996) Social Studies Now: use simple puppets to connect core subjects Instructor 106(1): 91

Logan, D. (2007). Puppetry. Brisbane, QLD, Australia: Brisbane Dramatic Arts Co.

Luckenbill, J. (2011). Circle time puppets: Teaching social skills. Teaching Young Children 4(4): 9-11.

MacDonald, R., and Jolliffe, L. (2003). Cultural Rural Tourism. Annals of Tourism Research 30 (2):307322.

Malkanthi, S. (2016). Traditional Art of string puppetry in Sirlinka convention for the safeguarding of the intangible cultural heritage. 28 November to 2 December2016, Eleventh session Addis-Ababa Ethiopia: 4552.

Martin, H. (1936). The library quarterly information, community, policy 6(4):405-418.

Measelle J, Ablow, P, and Cowan,C.(1998). Assessing young children's views of their academic, social, and emotional lives: An evaluation of the self-perception scales of the Berkeley puppet interview. Child Development 69: 1556-7

OECD. (2008), the Impact of Culture on Tourism. OECD Publishing.

Paccuulio, M., and Machado, L. (2016). Puppets as a strategy for communication with Brazilian children with cancer Nursing and Health Sciences, Journal of Health 18(1): 30-37.

Pelicand J., Gagnayre,R., Berthon,S., and Aujoulat,L. (2006). A therapeutic education programme for diabetic children: Recreational, creative methods, and use of puppets. Patient Education and Counseling 60: 152-63. 
Punch, S. (2002). Research with children: the same or different from research with adults? Journal of Social Studies 19: 21-41.

Salmon, M., and Sainato, D. (2005). Beyond Pinocchio: Puppets as teaching tools in inclusive early childhood classrooms. Young Exceptional Children 8(3): 12-19.

Schmidt, C. (2002). Comparison of three teaching methods on 4- through 7-year-old children's understanding of the lungs in relation to a peak flow meter in the management of asthma: A pilot study. Journal of Asthma 39: 641-648.

Schrandt, J. Townsend, D., and Poulson, C. (2009). Teaching empathy skills to children with autism. Journal of Applied Behavior Analysis 42:17-32.

Sinclair, R. (2004). Participation in Practice: making it meaningful, effective and sustainable. Child, 18:106-118.

Sparapani V, Jacob E, Montigny F. (2014). The use of puppets as a strategy for communicating with children with type 1 diabetes mellitus. Journal of Nursery Education Practing 4:186-194.

Synovitz, L. (1999). Using puppetry in a coordinated school health program. Journal of School Health 69 (4):145-147.

Tytti, O. (2012). "Shadow puppetry brightens those dark days". GB-Times, P24.

VanSchuyver, J. (1993). Storytelling made Easy with Puppets. Phoenix, Ariz: Oryx Press; P29.

Walker, L. (1988). Stress and coping in siblings of childhood cancer patients. Nursing Research 37: 208212.

Zahr, K. (1998). Therapeutic play for hospitalized preschoolers in Lebanon. Pediatric Nursing 24: 449-454.

مسرح العرائس : تأصيل الوطنية ورفع الوعى السياحى للأطفال المصربين

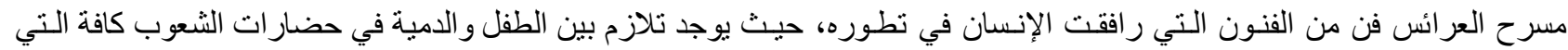

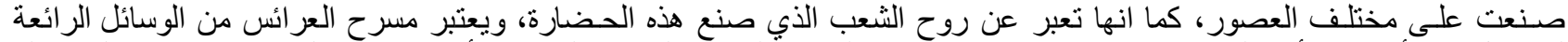



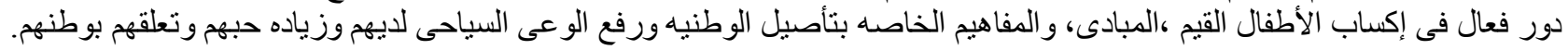

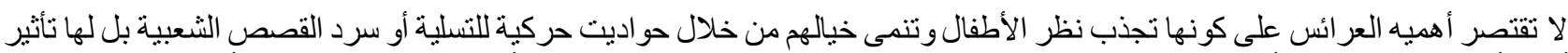

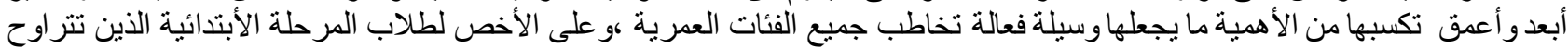

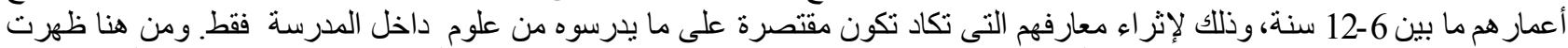

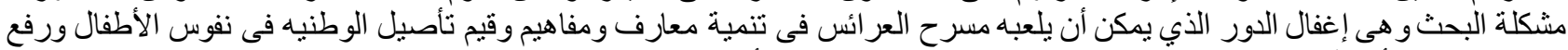

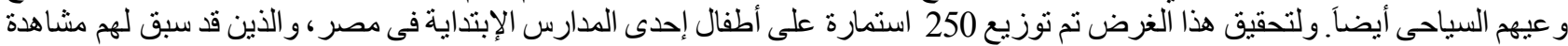

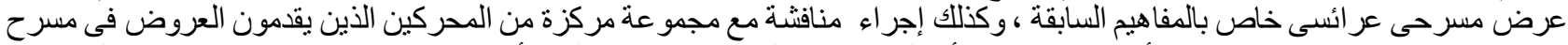
القاهرة للعرائس. وقد كثفت النتائج أن العر ائس هى أسهل وسيلة لنقل المعرفة للاطفال، و أداه تعليمية غير مباثرة لتنقيف الطفل وتنمية 